\title{
Measurements of the microhardness and compression testing of ferroelectric lead nitrate phosphate single crystals
}

\author{
C C DESAI and M S V RAMANA \\ Department of Physics, Sardar Patel University, Vallabh Vidyanagar 388 120, India \\ MS received 4 July 1987; revised 28 September 1987
}

\begin{abstract}
Ferroelectric crystals of lead nitrate phosphate (LNP) have been grown employing the controlled reaction between lead nitrate and orthophosphoric acid. The microhardness of LNP crystals has been determined. The effect of annealing and quenching on the mechanical properties of these crystals has been studied.
\end{abstract}

Keywords. Hardness; indentation; plasticity; cracks; indentation mark; compression; microhardness.

\section{Introduction}

Hardness is an important solid state property (Buckle 1959) commonly studied to determine the mechanical strength and other properties of materials. Point indentation techniques such as Vicker's pyramidal test, Hertz test and Knoop test have been commonly used to study glide, deformation anisotropy, cracks, etc in various materials. The Vicker's test is reliable for hardness measurements since it is independent of pre-existing surface flaw conditions (Haranoh et al 1982), is less timeconsuming (Weber and Matzke 1984) and can yield a better statistical average with fewer indentations. Katakov and Yamada (1977) studied the yield strength and dislocation mobility of $\mathrm{KCl}-\mathrm{KBr}$ solid solution single crystals. Grigorovish (1968) showed that microhardness is sensitive to the indented surface symmetry and its energy. Plendle and Gieliese (1962) correlated the hardness of several crystals with their lattice energy. Julg (1978) drew quantitative information about the bond strength from hardness values.

Ferroelectric lead nitrate phosphate (LNP) crystals show many interesting physical properties such as piezoelectric, optical and other characteristics. They are used in transducers and many linear and nonlinear mechanical devices. They are also suitable for verifying the microscopic theory of ferroelectricity. Data concerning the mechanical properties of LNP crystals have not so far been reported in the literature. In this paper, the results of our studies on the mechanical properties derived from plastic deformation are presented. The results of compression testing up to breaking point of the crystal are also described.

\section{Experimental}

Single crystals of LNP were grown using the controlled reaction between $\mathrm{H}_{3} \mathrm{PO}_{4}$ and $\mathrm{Pb}\left(\mathrm{NO}_{3}\right)_{2}$ by diffusion in silica gels (Desai and Ramana 1987). The crystals were examined by scanning electron microprobe analysis, X-ray diffraction, density measurements and thermogravimetric analysis. These techniques confirmed that they were LNP (monoclinic, space group $\left.P 2_{1} / c\right)$. The LNP crystals $\left(6 \times 4 \times 3 \mathrm{~mm}^{3}\right)$ with smooth surfaces and free from microstructures were selected and indentation studies 
were made on as-grown (001) surface with the indentor diagonal along [010] and [100] directions. These were made on dislocation-free regions using a microhardness indentor (Vicker's model 6270). The pyramidal diamond indentor is fixed to the front lens of the reproducing objective whose optical data are those of the standard 32/0.65 apochromats. The hardness tester with an optical device to indicate the testing load was attached to an incident-light microscope (Vicker's projection microscope), with the vertical illuminator replacing a standard objective. An indentation load (10 to $100 \mathrm{~g}$ ) can be used for this model. The indentation impression was measured by using a filer micrometer eyepiece which resembled the standard micrometer eyepiece in design, with a least count of $10 \mu \mathrm{m}$. To measure the diagonal of the impression and the length of the cracks, a high power objective replaced the reproducing objective of the indentor. The value of microhardness (Vickers hardness numerals, VHN) was calculated using the expression

$$
\mathrm{VHN}=1 \cdot 854 P / d^{2}
$$

where $P$ is the applied load in $\mathrm{kg}$ and $d$ the mean diagonal length of the indentor impression in $\mathrm{mm}$.

The probable mean error was calculated based on 10 indentations for a given plane and environment. Due to slight deviation from the normal incidence of the indentor on the crystal surface, two of the four vertices of the indentation impression were not well-defined on some of the samples and in such cases the measurements of length of diagonals were not accurate. To minimize the error, half diagonals were measured. The samples were maintained at $100^{\circ} \mathrm{C}$ for $24 \mathrm{hr}$ and cooled to room temperature at $5^{\circ} \mathrm{C} \mathrm{hr}^{-1}$ to anneal the crystal. The crystals were kept at different quenching temperatures for a fixed period and quenched to room temperature.

The applied pressure per unit volume of the crystal necessary for breaking was determined using a compression testing machine (Instron). For this purpose, visible transparent LNP crystals were selected and their dimensions were carefully determined using a travelling microscope. The crystal was placed between the two compression heads of the Instron machine, the upper head being slowly moved downword at a uniform speed of $0.5 \mathrm{~cm} \mathrm{~min}^{-1}$ and the record chart speed was $50 \mathrm{~cm} \mathrm{~min}{ }^{-1}$. The load applied and the resulting compression were recorded for various crystals. The upper head of the compression was moved until the crystal was crushed at the end of the plastic limit.

\section{Observations and discussion}

\subsection{Microhardness testing}

It was difficult to obtain cleaved surfaces of LNP crystal and therefore plane surfaces, microscopically free from signs of any damage, were chosen for indentation. Figure 1 shows the impression of an indentation inflicted on the (001) as-grown surfaces of the crystals at load of $30 \mathrm{~g}$, the indented impression being approximately square. It also shows that several cracks or median vents grow simultaneously from the concentration points, the sharp indentation edges. No preferred directions of venting were observed as in the case of anisotropic materials where the vents tend to have a preferred orientation (Dekker and Rieck 1974). Even for low loads, the deformation was too severe and near the indentation mark, the displaced matter 


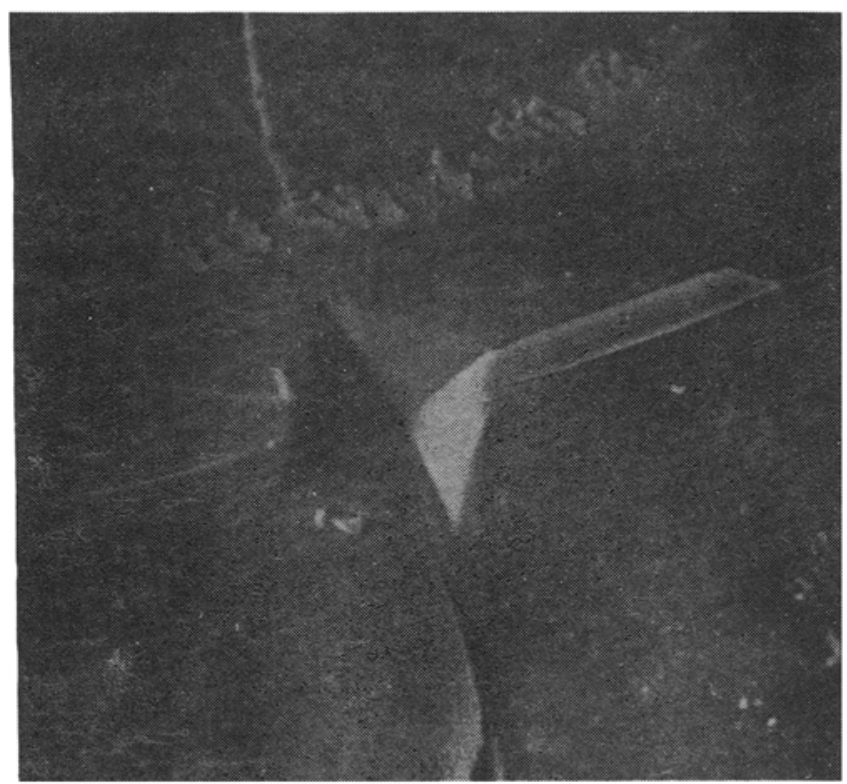

Higure 1. Typical indentatuon mark on (00)1) as-grown surface of LNP crystal $(\times 200)$.

chipped off as observed on the minerals. However, this chipping off does not change the size of the indentation mark, if diagonal ends can still be observed. The basic sequence of the crack propagation events is explained below (Lawn and Wilshaw 1975).

The sharp point of the indentor produces an elastic deformation and at some threshold, a deformation-induced flow suddenly develops into a small crack, the median vent on a plane containing the contact axis and the increase in load causes further stable growth of the median vents. On unloading, the median vents begin to close but do not heal. Relaxation of deformation materials within the contact zone, just before the removal of the indentor, superimposes intense residual tensile stresses upon the applied load and extending cracks called "lateral vents" begin to appear sideways. The lateral vents continue to extend and cause chipping.

The present experimental data fit equation (1) well in the load range studied (10 to $80 \mathrm{~g}$ ). Microhardness measurements revealed that VHN is independent of loading time or dwell time but is a function of an indentor load. The variation of hardness with load for quenched, annealed and room temperature samples is illustrated in figure 2. In all cases it was observed that microhardness increases with load giving a sharp maximum at $25 \mathrm{~g}$ and consistency in VHN are revealed after $50 \mathrm{~g}$. The absolute value of $\mathrm{VHN}$ in the case of quenched sample is greater than that of specimens at room temperature and annealed crystals.

During indentation, the indentor penetrates to a depth comparable to (or greater than) the thickness of the distorted zone. Since this zone is pierced by the indentor, its effect will be marked at comparatively low loads, consequently a noticeable increase in VHN is observed in the beginning, when the chipping of the material from the surface is very intense. As the depth of impression of the diamond pyramid increases with load, the effect of distorted zone decreases and hence the load dependence of microhardness is less. This explains that the variation of VHN with load is 


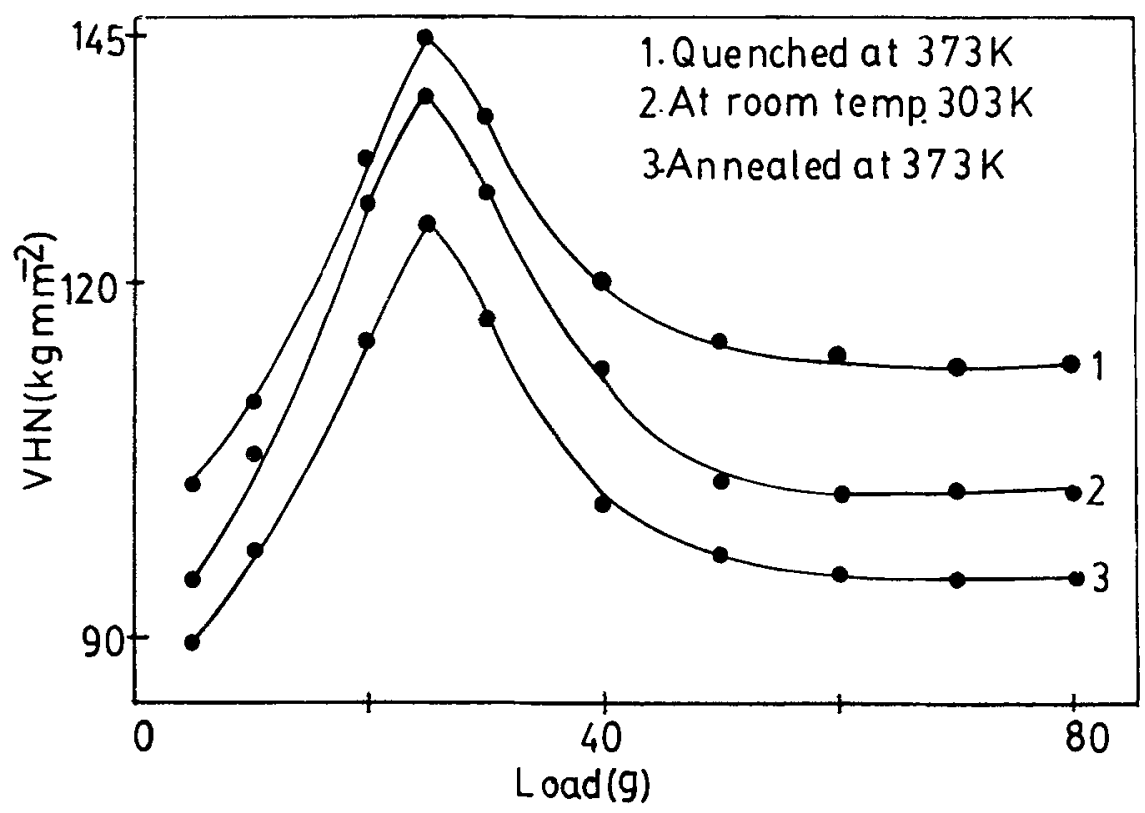

Figure 2. Plots of Vickers hardness numerals (VHN) against loads for (i) quenched. (ii) room temperature and (iii) annealed samples.

almost zero beyond $50 \mathrm{~g}$. For large loads (above $50 \mathrm{~g}$ ) when the indentor reaches a depth at which undistorted material exists, the microhardness is independent of load. Figure 2 also illustrates that annealing decreases the hardness whereas quenching increases the hardness for all loadings on (001) as-grown surfaces. This may be attributed to the quenching process as it introduces a large number of line and point defects and also results in the creation of internal stresses. Annealing, on the other hand, is a thermally activated process which leads to an arrangement of the existing dislocations and other defects into low energy configuration or total or partial annihilation.

The graph of $\log P$ vs $\log d$ (figure 3) gives two straight lines with different slopes for quenched, annealed and room temperature samples. VHN for all samples increases up to $25 \mathrm{~g}$ then decreases up to $50 \mathrm{~g}$. Correspondingly, the $\log P$ vs $\log d$ plots give two straight lines in all cases with slopes $2 \cdot 1$ and $1 \cdot 1$ at low and high loadings for (001) as-grown surfaces which proves the validity of the Mayer's equation

$$
P=a d^{n}
$$

where $P$ is the load applied $(\mathrm{g}), d$ the observed length of indentation mark $(\mathrm{mm})$ and $a$ (standard hardness) and $n$ are constants. Though $n=2$ is satisfied in the initial conditions, the concept of Onitsch (1947) seems to be more appropriate, i.e. if $n>2$ the hardness number decreases with increase in load but if $n<2$, hardness increases as load increases.

\subsection{Instron compression testing}

The plot of Instron compression recorded obtained for LNP single crystals is shown 
n figure 4. It is observed that when the crystal is pressed perpendicular to the (001) lane, Hooke's law is obeyed in the complete region upto breaking point without

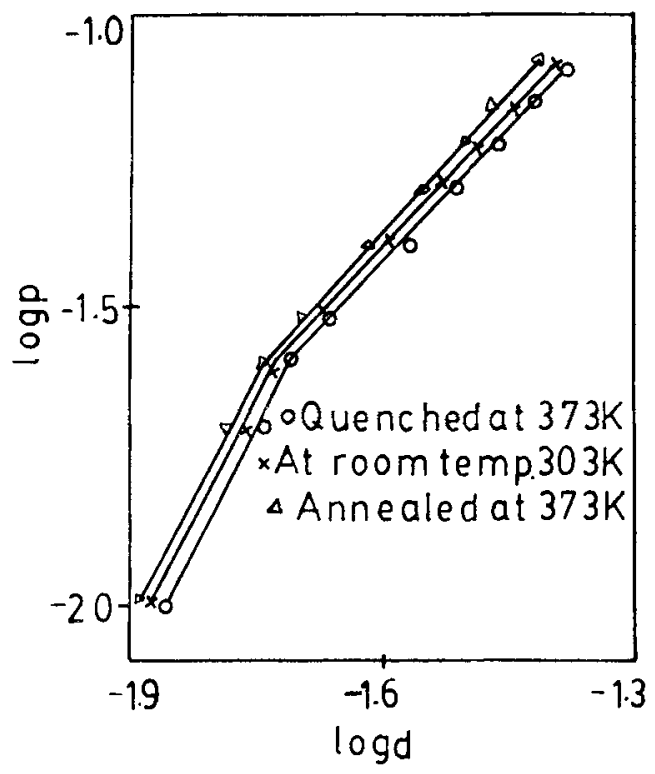

Vigure 3. Graphs of log $P$ against log $d$ for (1) quenched (O) (ii) room temperature $(x)$ and (iii) annealed samples $(\Delta)$.

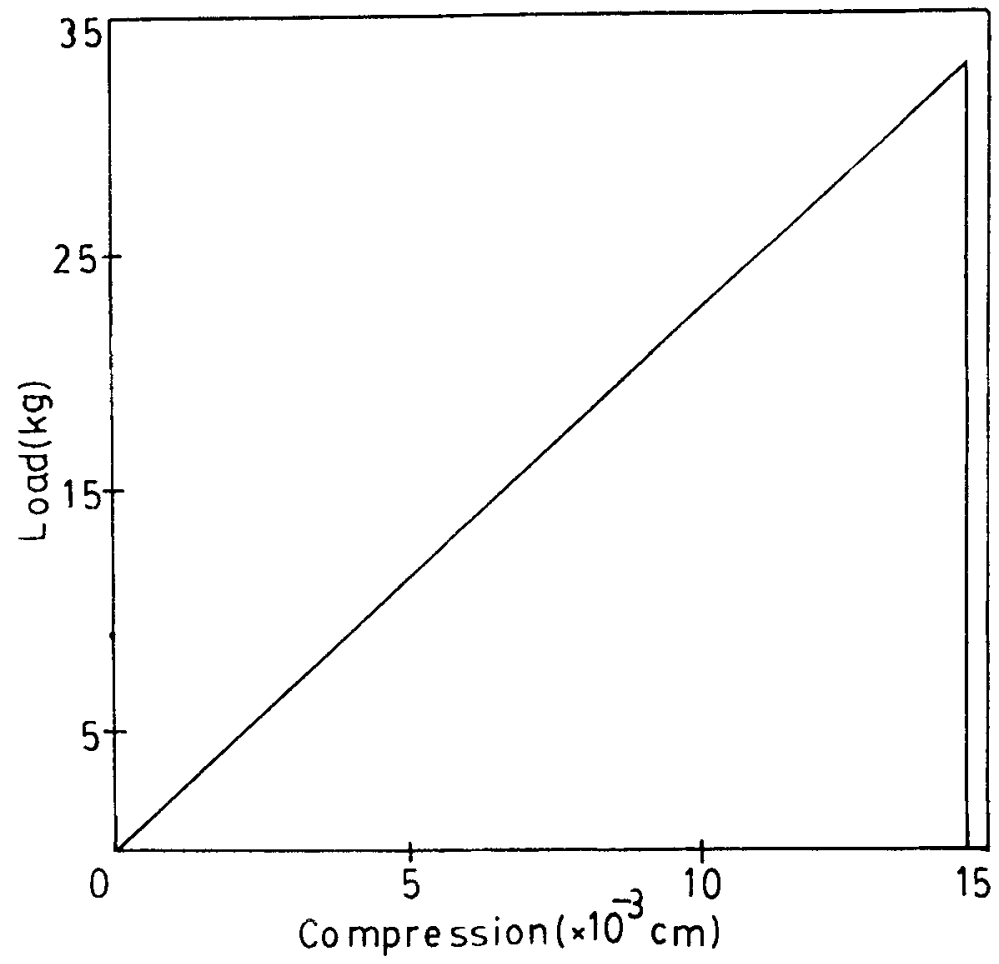

Figure 4. Instrun plot of applied load vs compression for $(001)$ as-grown surface. 
Table 1. Determination of Young's modulus of LNP crystals (crystal plane: 001)

\begin{tabular}{lcccccc}
\hline $\begin{array}{l}\text { Crystal } \\
\text { thickness } \\
(\mathrm{cm})\end{array}$ & $\begin{array}{c}\text { Crystal } \\
\text { area } \\
\left(\mathrm{cm}^{2}\right)\end{array}$ & $\begin{array}{c}\text { Compressibility } \\
(\mathrm{cm})\end{array}$ & $\begin{array}{c}\text { Load } \\
\left(\times 10^{6} \text { dynes }\right)\end{array}$ & Strain & $\begin{array}{c}\text { Stress } \\
\left(\mathrm{kg} \mathrm{cm}^{-2}\right)\end{array}$ & $\begin{array}{c}\text { Young's } \\
\text { modulus } \\
\left(\times 10^{9}\right. \\
\text { dynes cm }\end{array}$ \\
\hline 0.109 & 0.1888 & 0.0184 & 49 & 0.1688 & 259.4 & 1.5370 \\
0.086 & 0.1281 & 0.0145 & 33 & 0.1686 & 256.3 & 1.5321 \\
\hline
\end{tabular}

passing through 'a plastic region and the crystals just get randomly crushed into microbits. Crystals with different thickness were taken and the corresponding stress and strain were determined and the Young's modulus of LNP evaluated. The results are shown in table 1.

The present work suggests that (i) LNP crystals are highly brittle, because even at low indentation loads, fracture occurs at stress concentration points, (ii) VHN of LNP crystals is dependent on the applied load but is independent of the duration of loading, (iii) quenching increases the hardness of LNP crystals whereas annealing decreases the hardness, (iv) thermal treatment influences the dislocation mobility as a result of changes in the state and distribution of point defects in the crystal lattice and (v) Young's modulus of LNP crystals is $1.53 \times 10^{9}$ dynes $\mathrm{cm}^{-2}$.

\section{Acknowledgements}

The authors thank CSIR, New Delhi for financial assistance. One of us (CCD) thanks Mrs Aruna Desai and Mr Vishnu Desai (USA) for their interest.

\section{References}

Buckle H 1959 Met. Rev. 449

Desai C C and Ramana M S V 1987 Cryst. Res. Technol. 22731

Dekker E H and Rieck G D 1974 J. Mater. Sci. 91839

Grigorovish V K 1968 (Moscow: Scleromenry, Nauka) USSR pp 71-76

Haranoh T, Ishikawa H, Shinkai N and Mizuhashi M 1982 J. Mater. Sci. 12595

Julg A 1978 Phys. Chem. Miner. 3139

Katakov T and Yamada T 1977 J. Appl. Phys. 161119

Lawn B and Wilshaw R 1975 J. Mater. Sci. 101049

Onitsch E M 1947 Microskopie 2131

Plendle J N and Gieliese P J 1962 Phys. Rev. 125828

Weber W J and Matzke H 1984 J. Mater. Sci. 192533 